\title{
Kemampuan Tampungan Sungai Code Terhadap Material Lahar Dingin Pascaerupsi Gunungapi Merapi Tahun 2010
}

\author{
Widodo B., ${ }^{1}$ Ribut L., ${ }^{2}$ dan Hamidin ${ }^{2}$ \\ ${ }^{1}$ Jurusan Teknik Lingkungan FTSP UII; ${ }^{2}$ Pusat Studi Lingkungan (PSL) UII \\ ${ }^{1}$ email: widodo.bronto@gmail.com dan widodo_indo@yahoo.com
}

\begin{abstract}
Abstrak
Gunungapi Merapi merupakan gunungapi paling aktif di Indonesia Potensi bahaya vulkanik Gunungapi Merapi salah satunya adalah bahaya sekunder berupa aliran lahar dingin. Salah satu sungai yang memiliki resiko kerugian besar adalah Sungai Code, karena sungai ini melintasi Kota Yogyakarta yang padat permukiman. Penelitian ini dilakukan untuk melakukan estimasi kemampuan tampungan Sungai Code terhadap volume lahar dingin serta estimasi kebutuhan waktu untuk mengembalikan kondisi Sungai Code seperti sebelum erupsi terjadi. Metode penelitian dilakukan dengan kombinasi metode survey lapangan dan metode analisis matematis menggunakan teknik GIS (Geographic Information System) 3 (tiga) dimensi dengan metode cut and fill. Hasil estimasi volume sedimen lahar dingin di Sungai Code adalah sebesar 8389444,531 $\mathrm{m}^{3}$. Sungai Code masih mampu menampung lebih banyak sedimen lahar dingin yaitu sebanyak $12404689.844 \mathrm{~m}^{3}$ artinya dari kapasitas yang dimiliki, Sungai Code baru mengambil 40,34\%. Hasil survey menunjukkan dalam 1 hari $2696 \mathrm{~m}^{3}$ pasir dan batu sedimen lahar dingin yang mampu diambil. Hasil perhitungan estimasi menyimpulkan bahwa diperlukan waktu 3112 hari ( \pm 8,5 tahun) untuk normalisasi Sungai Code seperti sebelum erupsi tahun 2010.
\end{abstract}

Kata kunci: Erupsi Gunungapi Merapi, Lahar dingin, Tampungan, Sungai Code

\section{Pendahuluan}

Indonesia merupakan negara kepulauan yang memiliki 129 buah gunungapi aktif dan kurang lebih 500 buah gunungapi non aktif (Kaswanda, 1992). Salah satu gunungapi paling aktif di Indonesia adalah Gunungapi Merapi. Aktivitas Gunungapi Merapi dicirikan dengan periode letusan yang pendek dengan tipe letusan yang khas yaitu tipe merapi. Potensi bahaya vulkanik Gunungapi Merapi dapat dibedakan menjadi bahaya primer dan bahaya sekunder. Bahaya primer adalah bahaya yang ditimbulkan langsung oleh letusan yang biasanya disertai hamburan piroklastik, aliran lava, dan luncuran awan panas, sedangkan bahaya sekunder adalah bahaya yang ditimbulkan oleh aliran rombakan material lepas gunungapi yang bercampur dengan air hujan yang turun di puncak dengan konsentrasi tinggi yang disebut dengan aliran lahar (Wahyono, 2002).

Sub DAS Sungai Code luas keseluruhannya adalah sekitar 4.006,25 Ha. Melintasi tiga wilayah kabupaten/kota, yaitu; Kabupaten Sleman, Kota Yogyakarta dan Kabupaten Bantul. Sistem Sungai Code memiliki panjang total $\pm 41 \mathrm{~km}$, terdiri dari Sungai Code (sebelah hilir) panjang sungai 17 km dan Sungai Boyong (sebelah hulu) panjang sungai $24 \mathrm{~km}$. Material yang dikeluarkan selama erupsi tahun 2010 mencapai sekitar 100 juta meter kubik (BNPB RI, 2010). Seluruh sungai yang berhulu di Gunungapi Merapi berpotensi terhadap bahaya banjir lahar dingin. Kawasan sempadan di penggal tengah dan hilir Sungai Code yang melintasi perkotaan Yogyakarta cukup padat penduduknya. Hal ini menimbulkan potensi bahaya yang besar apabila terjadi banjir lahar dingin. 
Kondisi kerawanan banjir lahar dingin di Sungai Code memerlukan kajian terhadap kemampuan sungai menampung material lahar. Berdasar konsepsi dan kenyataan tersebut, penelitian ini dilakukan untuk melakukan estimasi kemampuan tampungan Sungai Code terhadap volume lahar dingin serta estimasi kebutuhan waktu untuk mengembalikan kondisi Sungai Code seperti sebelum erupsi terjadi.

\section{Metode Penelitian}

Data yang diperlukan dibedakan dalam bentuk data numerik/statistik serta data spasial. Data numerik yang diperlukan antara lain: Data sosial ekonomi dan kependudukan, Data morfometri sungai, Data hidrologi dan hidrolika, dan Data penambangan pasir eksisting. Data spasial yang juga diperlukan antara lain: Citra IKONOS sebelum sesudah erupsi Gunungapi Merapi tahun 2010, Citra ASTER sesudah erupsi Gunungapi Merapi tahun 2010, Citra Radar SRTM, serta Peta Rupa Bumi Indonesia Digital Skala $1: 25.000$.

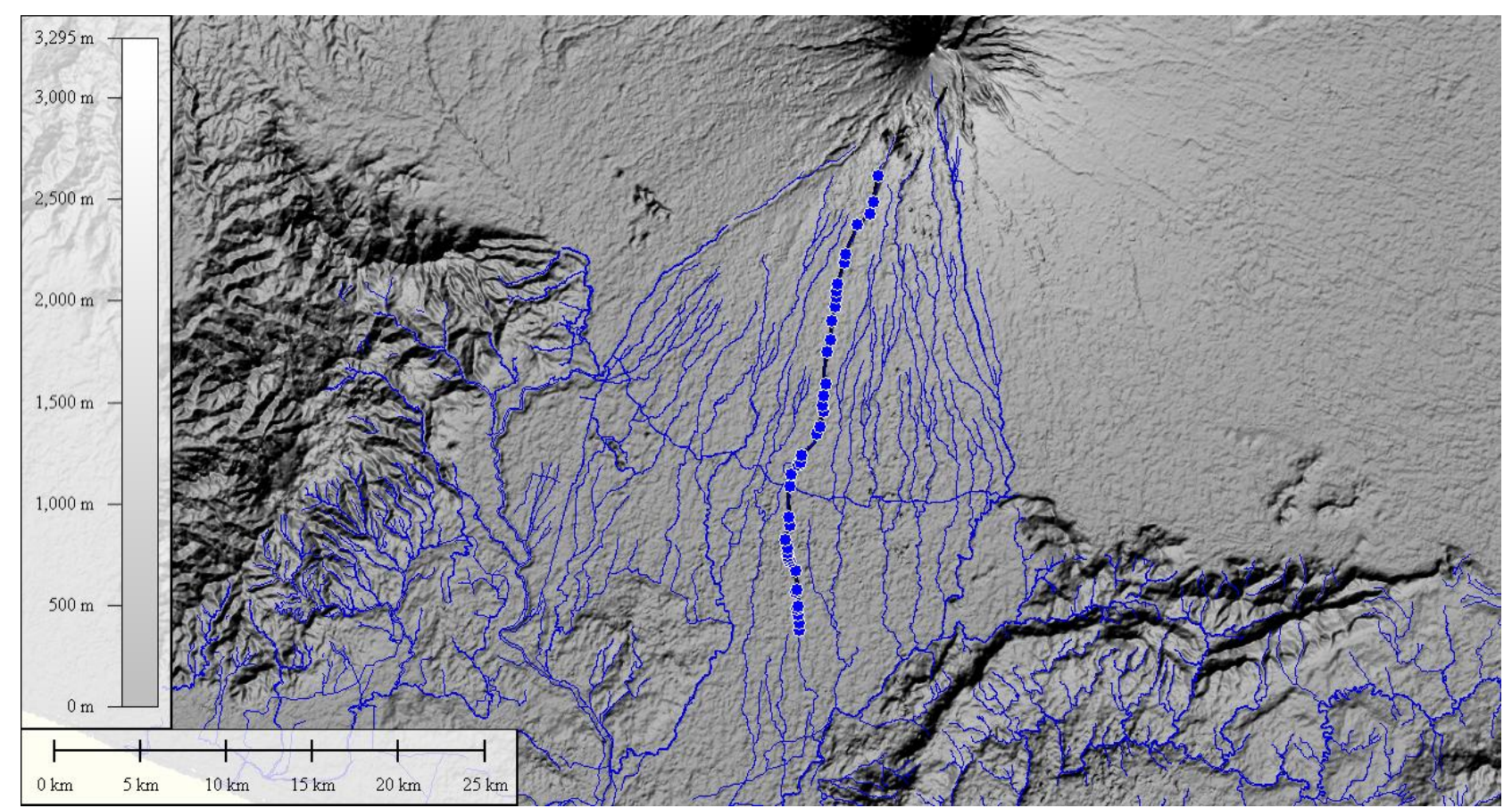

Gambar 1. Titik Sampling dan Profil Melintang Sungai Code

Data dikumpulkan secara instansional untuk data sekunder serta survey lapangan untuk data primer. Data sekunder yang dikumpulkan adalah data statistik/numerik dan data spasial. Survei lapangan dilakukan untuk checking dan mengetahui secara langsung kondisi endapan material Gunungapi Merapi di Sungai Code. Survey dan pengukuran dilakukan dengan metode sampling pada 40 titik di sepanjang Sungai Code dari Jembatan Wojo-Ringroad Selatan sampai dengan Sabo DAM Turgo/Gardu Pandang (Gambar 1). 
Analisis data dilakukan pada dua aspek, yaitu analisis penginderaan jauh dan analisis volume tampungan sedimen, dan estimasi waktu kemampuan menampung. Analisis Penginderaan Jauh digunakan untuk membuat peta morfometri DAS dan analisis jenis penggunaan lahan sekitar Sungai Code, terutama bagian hulu (Sungai Boyong). Berdasarkan hasil analisis penginderaan jauh dan survei dilakukan analisis tampungan dan perhitungan besaran sedimen material hasil erupsi Gunungapi Merapi yang mampu ditampung oleh Sungai Code, terumata bagian hulu (S. Boyong). Analisis terakhir adalah estimasi kemampuan Sungai Code menampung lahar dingin berdasarkan survey lapangan terhadap aktifitas pengerukan dan pengambilan endapan lahar di sepanjang Sungai Code serta hasil teoritis penelitian sebelumnya. Alur penelitian tersaji pada Gambar 2.

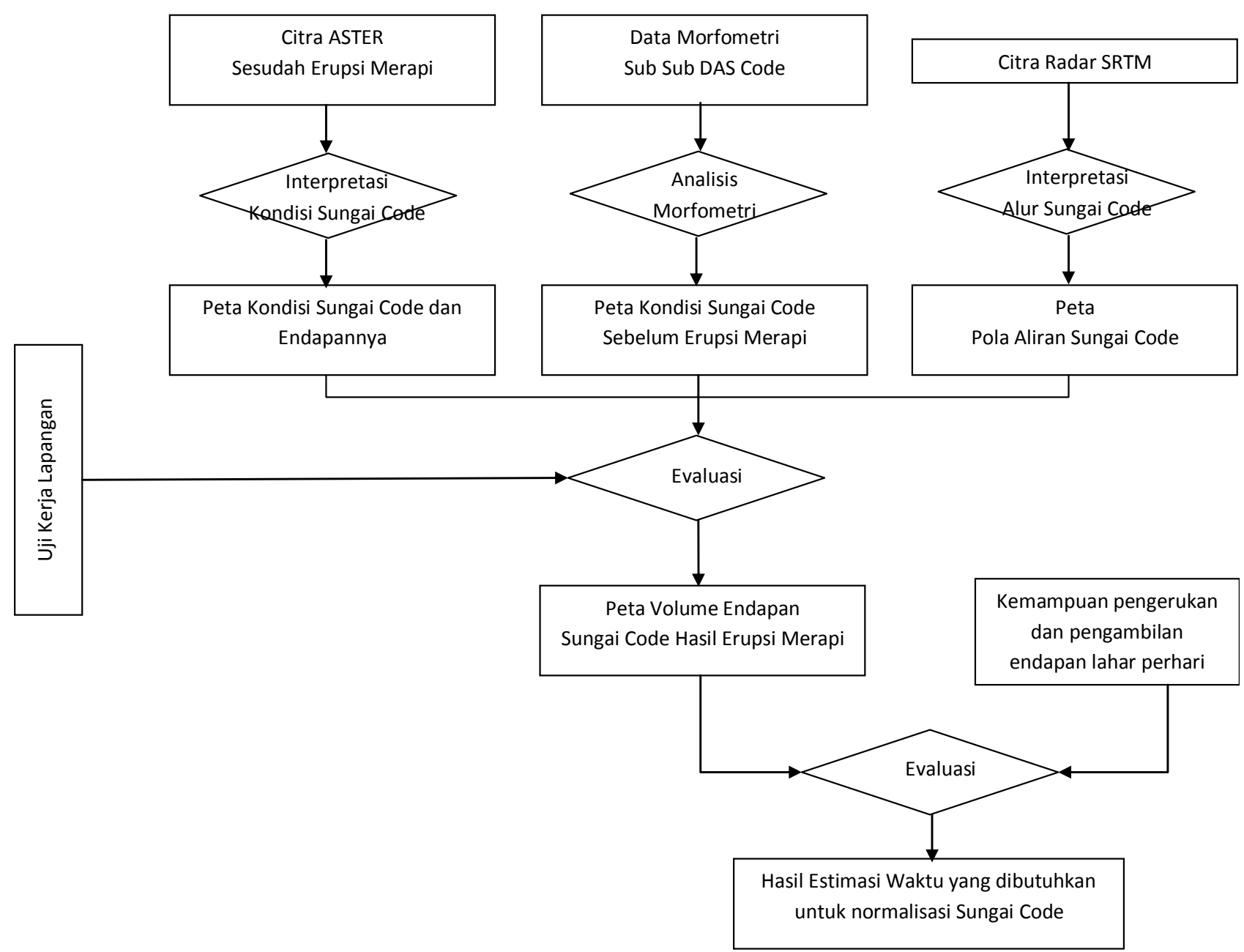

Gambar 2. Diagram Alir Penelitian

\section{Hasil Penelitian dan Diskusi}

Perhitungan mengenai volume sedimen hasil erupsi Merapi Tahun 2010 dan juga estimasi kapasitas/daya tampung sedimen, serta estimasi waktu yang dibutuhkan untuk normalisasi Sungai Code dilakukan berdasarkan data pengukuran di titik sampling . Data hasil estimasi yang dihasilkan adalah data ketebalan sedimen material lahar dingin di Sungai Code dari Titik Sampel 1 (Jembatan 
Wojo-Ringroad Selatan) sampai Titik Sampel 40 (Sabo DAM Turgo/Gardu Pandang). Hasil estimasinya adalah dalam perekaman sesaat pada waktu pengambilan sampel dengan tidak memperhitungkan debit aliran harian dan penambahan sedimen harian.
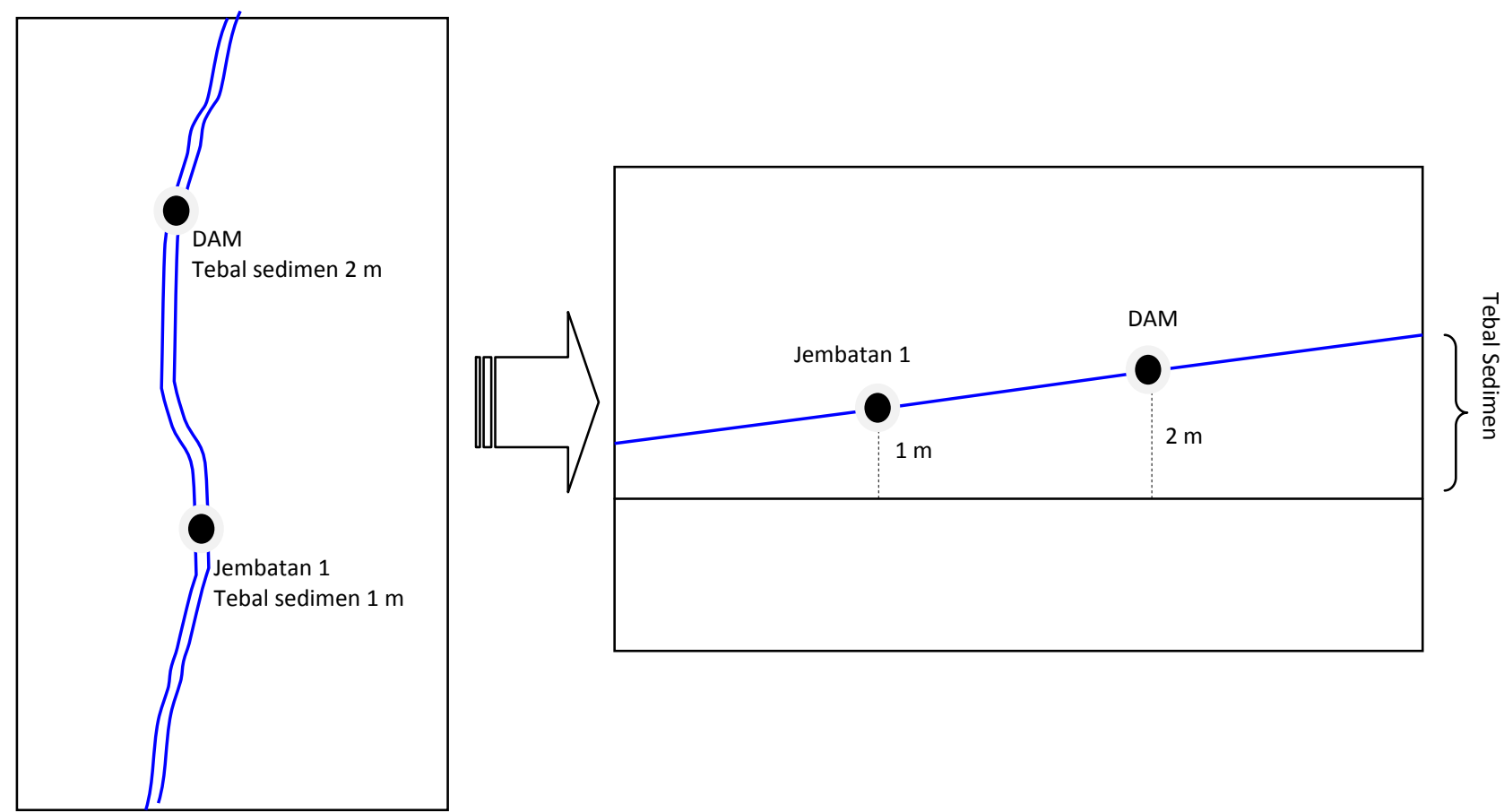

Gambar 3. Ilustrasi Interpolasi Berdasarkan Data Pada Tiap Titik Sampel Jembatan/DAM

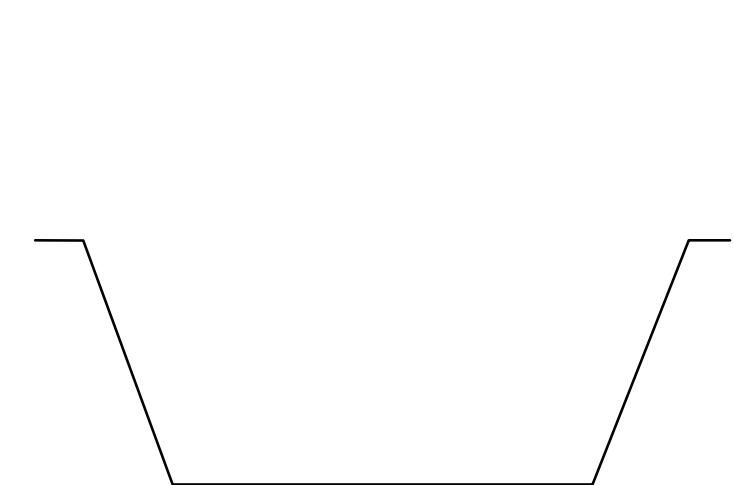

Profile Penampang Sungai di bawah jembatan
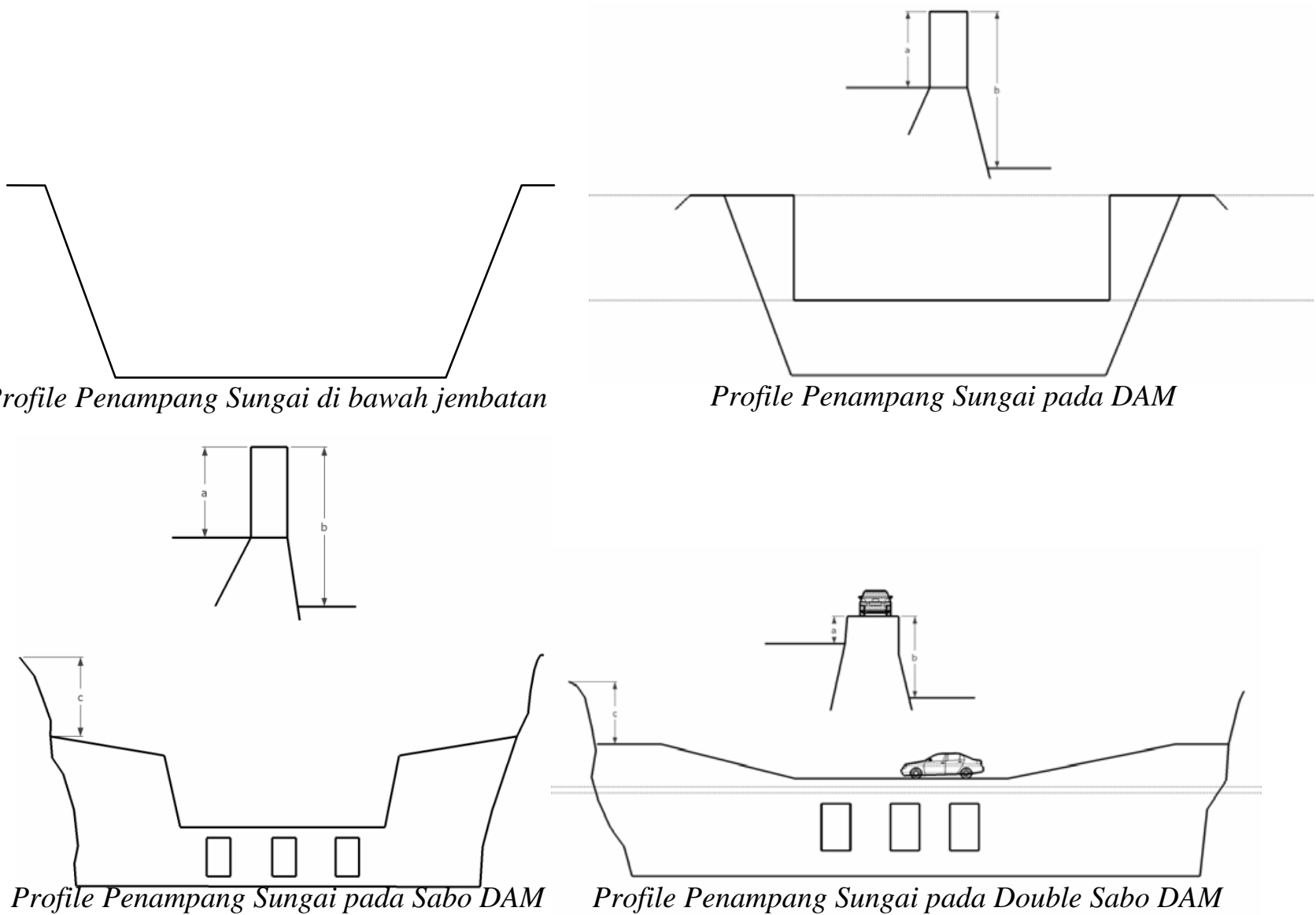

Profile Penampang Sungai pada DAM

Gambar 4. Ilustrasi Profil Penampang Sungai 
Metode yang digunakan dalam estimasi dengan pendekatan logika matematis. Asumsi yang digunakan adalah setiap jembatan dan DAM yang ada merupakan titik tertinggi sedimen yang terkumpul dan diinterpolasi ke arah hulu maupun hilir dari jembatan/DAM yang merupakan titik sampel. Ilustrasi interpolasi tersebut dapat dilihat pada Gambar 3.

Perhitungan menggunakan analisis GIS (Geographic Information System) 3 (tiga) dimensi dengan metode cut and fill yang dikembangkan oleh Environmental System Research Institute (ESRI) yang tertuang dalam perangkat lunak ArcView GIS. Prinsipnya adalah membandingkan DEM (Digital Elevation Model) ketebalan sedimen sebelum X dan sesudah X. Dalam konteks penelitian ini adalah membandingkan ketebalan sedimen sebelum erupsi Gunungapi Merapi dan sesudah erupsi Gunungapi Merapi serta memperhitungkan DEM saat seluruh Sungai Code tertutup sedimentasi hasil lahar dingin Gunungapi Merapi. Untuk memperkuat perhitungan dibuat pembeda antara profil melintang sungai di Jembatan, DAM, Sabo DAM dan Double Sabo DAM dengan Gambar 4.

\section{A. Estimasi Total Volume Sedimen}

Berdasarkan penerapan metode yang sudah dijelaskan di atas diperoleh hasil sebagai berikut:

1. Ketebalan sedimen terendah berada di titik-titik sampel yang berada di jembatan-jembatan di dalam Kota Yogyakarta yang ketebalannya berkisar antara 0,5 - $1 \mathrm{~m}$, serta lebar sungainya berkisar antara 11 - 43,3 m.

2. Ketebalan sedimen tertinggi berada di DAM, Sabo DAM dan Double Sabo DAM terutama di wilayah Kabupaten Sleman yang ketebalannya berkisar 3,36 - 11,20 m, serta lebar sungainya antara 30,2 - 191,4 m.

3. Hasil estimasi volume sedimen lahar dingin di Sungai Code dari titik sampel 1 - 40 dengan metode GIS cut and fill ESRI sebesar 8389444,531 $\mathrm{m}^{3}$. Hasil ini merupakan hasil perekaman sesaat pada waktu pengambilan sampel dengan tanpa mempertimbangkan debit aliran air dan penambahan sedimen dalam skala harian.

\section{B. Estimasi Kapasitas Tampungan Sedimen Sungai Code}

Berdasarkan penerapan metode di atas diperoleh hasil sebagai berikut:

1. Berdasarkan data hasil sampel antara jarak dari dasar sungai ke bibir Sungai Code diperoleh hasil berkisar antara 2,7 - 19,4 m.

2. Luas area Sungai Code dari titik sampel 1 - 40 adalah seluas $2521600 \mathrm{~m}^{2}$.

3. Hasil Estimasi kapasitas/daya tampung sedimen lahar dingin di Sungai Code dari titik sampel 1 - 40 dengan metode GIS cut and fill ESRI sebesar $20794134.375 \mathrm{~m}^{3}$. 
Berdasarkan waktu perekaman sesaat maka Sungai Code masih mampu menampung lebih banyak sedimen lahar dingin Gunungapi Merapi sebanyak $12404689.844 \mathrm{~m}^{3}$ atau dengan kata lain dari total 100\% volume kapasitas yang dimilikinya, Sungai Code baru mengambil 40,34\% -nya.

\section{Estimasi Waktu Yang Dibutuhkan Untuk Normalisasi Sungai Code}

Kemampuan penambang dalam mengambil pasir dan batu di Gunungapi Merapi dalam sehari cukup terbatas. Tabel 1 menunjukkan data kemampuan penambang dalam mengambil/mengeruk sedimen pasir dan batu dalam sehari.

Tabel 1. Kemampuan Penambang Pasir dan Batu di Sungai Code dalam Sehari

\begin{tabular}{|c|c|c|c|c|c|}
\hline No. & Lokasi & Jumlah & Jenis Tambang & $\begin{array}{c}\text { Jenis } \\
\text { Kendaraan }\end{array}$ & Volume $\left(\mathrm{m}^{3}\right)$ \\
\hline 1 & Sabo DAM Kemiri & $\begin{array}{c}100 \\
20\end{array}$ & $\begin{array}{l}\text { Pasir } \\
\text { Batu } \\
\end{array}$ & Truk & $\begin{array}{l}600 \\
120 \\
\end{array}$ \\
\hline 2 & Double Sabo DAM Tanen & $\begin{array}{l}70 \\
10\end{array}$ & $\begin{array}{l}\text { Pasir } \\
\text { Batu }\end{array}$ & Truk & $\begin{array}{c}420 \\
60\end{array}$ \\
\hline 3 & Depo Pulowatu & $\begin{array}{c}100 \\
10 \\
\end{array}$ & $\begin{array}{l}\text { Pasir } \\
\text { Batu }\end{array}$ & Truk & $\begin{array}{c}600 \\
60\end{array}$ \\
\hline 4 & Bulus (Garmen) & $\begin{array}{l}50 \\
10 \\
\end{array}$ & $\begin{array}{l}\text { Pasir } \\
\text { Batu }\end{array}$ & Truk & $\begin{array}{c}300 \\
60 \\
\end{array}$ \\
\hline 5 & DAM Wonorejo & $\begin{array}{c}50 \\
5\end{array}$ & $\begin{array}{l}\text { Pasir } \\
\text { Batu }\end{array}$ & Truk & $\begin{array}{c}300 \\
30\end{array}$ \\
\hline 6 & DAM Lojajar & $\begin{array}{c}10 \\
3\end{array}$ & $\begin{array}{l}\text { Pasir } \\
\text { Batu }\end{array}$ & Pick Up & $\begin{array}{c}20 \\
6\end{array}$ \\
\hline 7 & DAM Plemburan & 20 & Pasir & Truk & 120 \\
\hline \multicolumn{5}{|c|}{ TOTAL } & 2696 \\
\hline
\end{tabular}

Sumber: Hasl Survei Tahun 2010

Catatan: Kapasitas 1 truk $=6 \mathrm{~m}^{3}$, Kapasitas 1 Pick $U p=2 \mathrm{~m}^{3}$

Dari data di atas diketahui dalam 1 hari 'hanya' $2696 \mathrm{~m}^{3}$ pasir dan batu yang merupakan sedimen lahar dingin Gunungapi Merapi yang mampu diambil untuk menormalisasi Sungai Code. Sehingga apabila dihitung antara jumlah sedimen secara sesaat (bisa dianggap sehari) yang berhasil diestimasi yaitu sebesar 8389444,531 $\mathrm{m}^{3}$, maka memerlukan waktu 3112 hari ( \pm 8,5 tahun) untuk dapat menormalkan kembali Sungai Code seperti saat sebelum Erupsi Merapi Tahun 2010. Angka ini sekali lagi masih mengabaikan penambahan sedimen lahar dingin Gunungapi Merapi secara harian.

\section{Kesimpulan}

1. Estimasi volume sedimen lahar dingin di Sungai Code pada titik sampel dengan metode GIS cut and fill ESRI sebesar 8.389.444,531 $\mathrm{m}^{3}$.

2. Estimasi kapasitas tampungan sedimen lahar dingin di Sungai Code dari titik sampel 1 - 40 dengan metode GIS cut and fill ESRI sebesar 20.794.134.375 m³. 
3. Berdasarkan waktu perekaman sesaat maka Sungai Code masih mampu menampung lebih banyak sedimen lahar dingin Gunungapi Merapi, yaitu sebanyak 12.404.689,844 m³.

4. Sungai Code diestimasikan memerlukan waktu 3112 hari ( $\pm 8,5$ tahun) untuk normalisasi seperti saat sebelum Erupsi Merapi Tahun 2010.

\section{Ucapan Terima Kasih}

Penulis secara khusus menyampaikan terima kasih kepada: Direktorat Penelitian dan Pengabdian pada Masyarakat (DPPM) UII, Pemerintah Kabupaten Sleman, dan Tim Surveyor.

\section{Daftar Pustaka}

Alexander, D. (1991). Information Technology in Real Time for Monitoring and Managing Natural Disasters, Progress in Physical Geography, vol. 15, pp. 238-260.

BNPB. (2010). Laporan Harian Tanggap Darurat Gunung Merapi Tanggal 1 Desember 2010 pukul 24.00 WIB, Jakarta.

Kaswanda. (1992). Penginderaan Jauh dalam Menunjang Pemantauan Gunungapi di Indonesia, Prosiding IIPRS.

Katili, J.A., dan Marks, P. (1963). Geologi. Kilat Madju, Bandung.

Wahyono, Sri Agus. (2002). Kajian Tingkat Risiko Bahaya Vulkanik Melalui Teknik Penginderaan Jauh dan Sistem Informasi Geografis Lokasi Kasus Lereng Selatan Gunungapi Merapi Kabupaten Sleman Daerah Istimewa Yogyakarta. Tesis. Program Pasca Sarjana Universitas Gadjah Mada, Yogyakarta.

Widjoyo, S. (1994). Kontribusi Teknologi Penginderaan Jauh dan Sistem Informasi Geografik Dalam Pemantauan Bencana Alam, Simposium Nasional Mitigasi Bencana Alam, Universitas Gadjah Mada. 